\title{
Assessment of numerical procedures for determining shallow foundation failure envelopes
}

\author{
STEPHEN K. SURYASENTANA*, HELEN P. DUNNE†, CHRISTOPHER M. MARTIN†, \\ HARVEY J. BURD†, BYRON W. BYRNE† and AVI SHONBERG†
}

\begin{abstract}
The failure envelope approach is commonly used to assess the capacity of shallow foundations under combined loading, but there is limited published work that compares the performance of various numerical procedures for determining failure envelopes. This paper addresses this issue by carrying out a detailed numerical study to evaluate the accuracy, computational efficiency and resolution of these numerical procedures. The procedures evaluated are the displacement probe test, the load probe test, the swipe test (referred to in this paper as the single swipe test) and a less widely used procedure called the sequential swipe test. Each procedure is used to determine failure envelopes for a circular surface foundation and a circular suction caisson foundation under planar vertical, horizontal and moment (VHM) loading for a linear elastic, perfectly plastic von Mises soil. The calculations use conventional, incremental-iterative finite-element analysis (FEA) except for the load probe tests, which are performed using finite-element limit analysis (FELA). The results demonstrate that the procedures are similarly accurate, except for the single swipe test, which gives a load path that under-predicts the failure envelope in many of the examples considered. For determining a complete VHM failure envelope, the FEA-based sequential swipe test is shown to be more efficient and to provide better resolution than the displacement probe test, while the FELA-based load probe test is found to offer a good balance of efficiency and accuracy.
\end{abstract}

KEYWORDS: bearing capacity; finite-element modelling; footings/foundations; limit state design/analysis; numerical modelling; offshore engineering; soil/structure interaction

\section{INTRODUCTION}

In recent decades, there has been significant interest in the failure envelope approach for assessing the ultimate capacity of foundations under combined loading. The failure envelope is a hypersurface that defines the $n$-dimensional combination of loads $(n \geq 1)$ that results in the ultimate limit state (or plastic failure) of a foundation. The advantages of this approach over classical bearing capacity methods (Terzaghi, 1943; Meyerhof, 1951; Vesić, 1973) are manifold and have been widely discussed (Schotman, 1989; Tan, 1990; Nova \& Montrasio, 1991; Gottardi \& Butterfield, 1993; Bransby \& Randolph, 1998; Martin \& Houlsby, 2000; Houlsby \& Byrne, 2001; Gourvenec, 2007).

The failure envelope approach was first introduced by Roscoe \& Schofield (1957) to analyse the interaction between a steel frame and its foundations using envelopes of normalised forces. Since then, it has been widely adopted to represent the results of numerical studies of foundation bearing capacity, for a broad range of foundation types. For example, failure envelopes have been determined for surface foundations (Bell, 1991; Taiebat \& Carter, 2000,

Manuscript received 5 March 2018; revised manuscript accepted 28 January 2019. Published online ahead of print 5 March 2019.

Discussion on this paper closes on 1 June 2020, for further details see p. ii.

Published with permission by the ICE under the CC-BY 4.0 license. (http://creativecommons.org/licenses/by/4.0/)

* Department of Engineering Science, University of Oxford, Oxford, UK (Orcid:0000-0001-5460-5089).

$\dagger$ Department of Engineering Science, University of Oxford, Oxford, UK.

† Ørsted Wind Power, London, UK.
2010; Gourvenec, 2007; Vulpe et al., 2014; Shen et al., 2016, 2017), skirted or caisson foundations (Bransby \& Randolph, 1998; Bransby \& Yun, 2009; Gourvenec \& Barnett, 2011; Hung \& Kim, 2014; Karapiperis \& Gerolymos, 2014; Gerolymos et al., 2015; Vulpe, 2015; Mehravar et al., 2016), spudcan foundations (Zhang et al., 2011) and mudmat foundations (Feng et al., 2014; Fu et al., 2014; Nouri et al., 2014; Dunne \& Martin, 2017). However, there is limited published work that quantifies the performance of the numerical procedures used to determine these failure envelopes. Given the increasing need for site- and foundation-specific failure envelopes, either for macro-element modelling (e.g. Martin \& Houlsby, 2001; Cassidy et al., 2004) or for the assessment of ultimate limit states using the failure envelope approach, the performance of these numerical procedures is an important consideration.

The contributions of this paper are two-fold. First, it addresses the uncertainty around the performance of various numerical procedures by carrying out a systematic comparison of the failure envelopes determined by each procedure and by making an assessment of relative computational efficiency, albeit for a limited range of foundation types and loading conditions. The aim is to provide guidance for researchers to identify which procedure they should adopt for their studies, based on the criteria of accuracy, efficiency and resolution. This paper does not make assumptions on which particular parts of the failure envelope are more, or less, significant for design and thus there is no attempt to quantify or include the practical significance of errors (on the basis of where they occur in load space) in the criteria of the comparative study. Second, this study provides insights into the implementation of one of the less widely used numerical procedures called the sequential swipe test. As will be shown 
later, the number of discrete swipe stages used within a sequential swipe test has a significant impact on the accuracy of the failure envelope obtained.

\section{NUMERICAL PROCEDURES FOR DETERMINING FAILURE ENVELOPES}

The numerical procedures investigated in this paper can be categorised into two main groups: displacement-controlled and load-controlled. The displacement-controlled analyses (i.e. displacement probe test, single swipe test and sequential swipe test) are performed using the three-dimensional (3D) finite-element analysis (FEA) software, Abaqus version 6.13 (Dassault Systèmes, 2014). The load-controlled analyses (i.e. load probe test) are performed using the 3D finite-element limit analysis (FELA) software, OxLim (Makrodimopoulos \& Martin, 2006, 2007; Martin, 2011), which has been used to analyse various bearing capacity problems in plane strain (Martin \& White, 2012; Mana et al., 2013; Dunne et al., 2015) and more recently in three dimensions (Dunne \& Martin, 2017).

All of the analyses reported in this paper are total stress analyses carried out for undrained clay, modelled using the von Mises yield criterion. The von Mises criterion was chosen over the Tresca criterion primarily for convenience, as it is more efficient to solve von Mises problems than Tresca problems with the 3D FELA software, OxLim. However, it has been shown by Gourvenec et al. (2006) that vertical bearing capacity calculations using the von Mises criterion (with the strength in simple shear set equal to the undrained shear strength, $s_{\mathrm{u}}$ ) are reasonably close to those using the Tresca criterion. Furthermore, once the failure envelope has been normalised by the uniaxial capacities, the resulting shape of the non-dimensional failure envelope is qualitatively similar for both von Mises and Tresca soil - for example, compare the VHM failure envelopes for a circular surface foundation in this paper (shown later as Fig. 11(a)) to Fig. 10(a) in the paper by Gourvenec (2007). This paper is concerned more with the numerical approaches, rather than a particular soil model, and thus the adoption of a single soil model for the comparative study is accepted as a limitation of the scope of the paper.

In this paper, $V, H$ and $M$ refer to the vertical, horizontal and moment loads, respectively, and $w, u$ and $\theta$ refer to the corresponding vertical, horizontal and rotational displacements. The loading reference points (LRP) are located at the centres of the surface foundation base and the suction caisson lid base (refer to Fig. 1 for the adopted sign conventions). Note that this is different from some previous research where the LRP is located at the level of the caisson skirt base. Furthermore, failure envelopes are presented in terms of normalised loads $\left(\tilde{V}=V / V_{0}, \tilde{H}=H / H_{0}\right.$, $\tilde{M}=M / M_{0}$ ), which refer to loads normalised by their respective uniaxial capacities $\left(V_{0}, H_{0}, M_{0}\right)$ as determined using the same numerical procedure.

\section{Displacement probe test}

In the displacement probe test, a displacement increment in a prescribed direction is applied to the foundation from a zero load state, with the final (steady) load state determining a single point on the failure envelope. To find the full failure envelope, a series of these probe tests with varying displacement directions must be completed. The displacement probe test has robust convergence properties, and provided that the prescribed displacement magnitude is sufficiently large, a well-defined failure load (or combination of loads) can be obtained.

However, this approach is relatively inefficient as each calculation only determines a single point on the failure envelope. Furthermore, it does not allow a straightforward investigation of the failure envelope as the load path followed during a displacement probe test is typically non-linear and difficult to predict. For example, the schematic diagram in Fig. 2(a) shows a representative, non-linear load path followed during a displacement probe. The initial load path is determined by the elastic stiffness of the soil-foundation system and the prescribed displacement direction. However, as soil yielding occurs, the stiffness reduces by differing amounts in each of the loading directions and the load path changes direction before arriving at (and possibly tracking along) the failure envelope, eventually maintaining a steady load state as the displacements continue to increase.

\section{Load probe test}

In the load probe test, combined loading components in a prescribed ratio are applied to the foundation until failure occurs. It can be difficult to determine accurate failure loads with load control in FEA, as convergence generally cannot be obtained if the final prescribed load exceeds the foundation capacity. A series of trial-and-error load cases, or a careful approach to the failure envelope, is therefore required to determine the maximum load that can converge. However, the FELA technique does not suffer from such issues and hence, FELA was adopted for the load probe tests in this study. Furthermore, the use of both lower-bound and upper-bound FELA provides a rigorous bracket on the theoretical failure load. A key advantage of the load probe test is that the predefined direction is followed throughout the analysis, which enables a more straightforward approach to determining the entire failure envelope. The schematic diagram in Fig. 2(a) shows the process of determining a $\mathrm{VH}$ failure envelope by probing in load space. Once a loading ratio is defined, each of the load paths travels from the origin

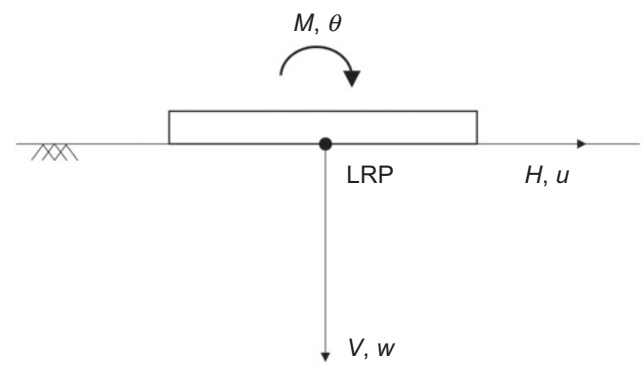

(a)

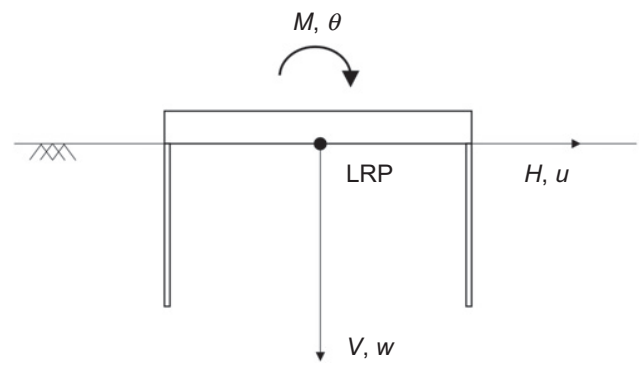

(b)

Fig. 1. Sign conventions for loads $(V, H, M)$ and displacements $(w, u, \theta)$ : (a) surface foundation; (b) caisson foundation. LRP denotes loading reference point 


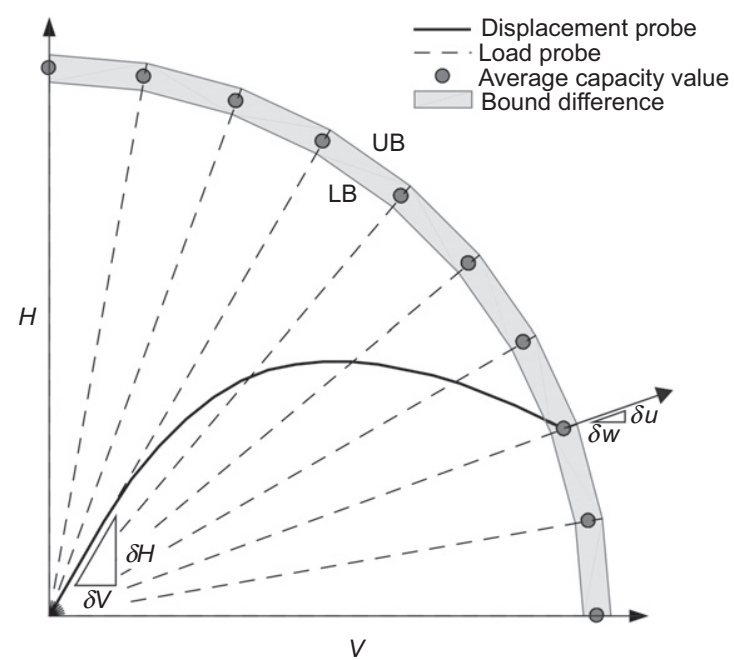

(a)

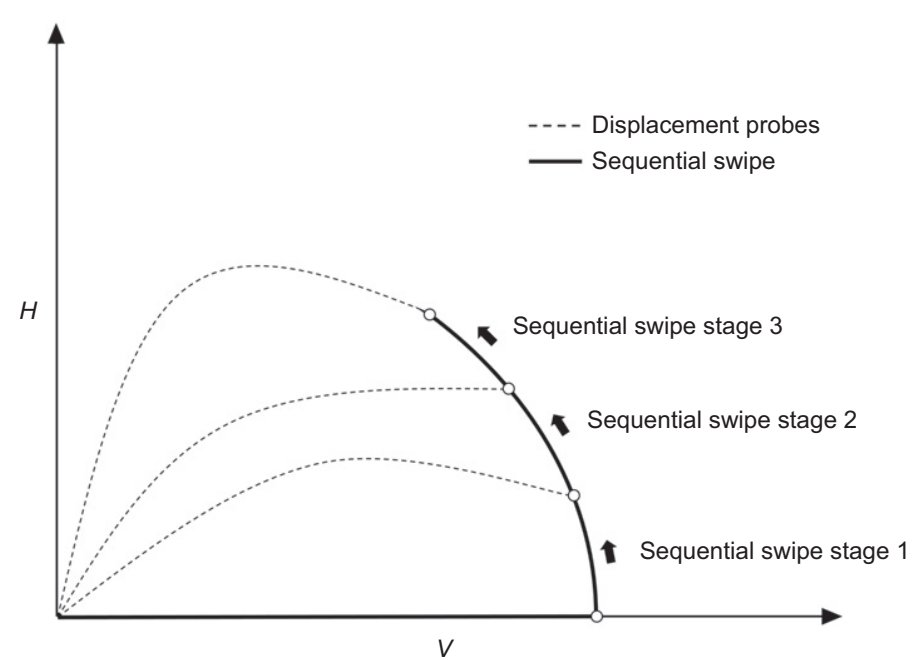

(b)

Fig. 2. (a) Schematic representation of load paths during displacement probe and load probe tests in $V H$ space. For a displacement probe test, the initial load path is determined by the elastic properties of the system - that is $\delta H / \delta V=\left(k_{H}^{\mathrm{e}} / k_{V}^{\mathrm{e}}\right)(\delta u / \delta w)$, where $k_{H}^{\mathrm{e}}, k_{V}^{\mathrm{e}}, \delta u$ and $\delta w$ are the elastic horizontal stiffness, elastic vertical stiffness, horizontal displacement and vertical displacement, respectively. As the soil starts yielding, the load path changes non-linearly before arriving at the failure envelope and settling to a steady load state as the displacements continue to increase. For a load probe test, the load path is always co-directional with the load probe direction. (b) Difference in load paths taken by three displacement probe tests and by a sequential swipe test using the same three probe directions

(or other initial load states) in the prescribed direction until the failure envelope is reached.

\section{Single swipe test}

The original form of the single swipe test, also known as the sideswipe test, was introduced by Tan (1990) to investigate the $V H$ failure envelope of a surface foundation using centrifuge model tests. In a sideswipe test, the foundation is first pushed vertically to a prescribed embedment, after which the vertical displacement is held constant while the foundation is 'swiped' horizontally. This test was generalised to VHM loading by Martin (1994), Gottardi et al. (1999) and Byrne (2000), among other researchers. Subsequent numerical studies (e.g. Bransby \& Randolph, 1998; Gourvenec \& Randolph, 2003) then applied this technique to a range of load spaces by following the same principle of applying displacement in one degree of freedom (DoF), followed by a displacement in another DoF while the displacement in the first DoF is held constant. This process is essentially two displacement probe tests applied in sequence.

A fundamental assumption underpinning this type of test is that the swipe phase results in a load path that tracks closely along the failure envelope, using analogies with hardening plasticity theory as applied in critical state soil mechanics (e.g. see the discussions in Tan (1990), Martin (1994) and Martin \& Houlsby (2000)). Unfortunately, this assumption does not always hold when generalised single swipe tests are applied to shallow foundations, as the load path may deviate inside (or cut across) the failure envelope and thus underpredict the capacity (Bransby \& Randolph, 1998).

\section{Sequential swipe test}

Although the sequential swipe test is a less widely used procedure for determining failure envelopes, it can resolve the potential under-prediction behaviour of the single swipe test referred to above. A sequential swipe test is a multi-swipe test, which applies a more gradual change in direction (in displacement space) by way of a series of discrete swipe stages, compared with the abrupt directional change that occurs in the single swipe test. This type of test first appeared in physical experiments (Martin, 1994; Byrne, 2000; Martin \& Houlsby, 2000) under the term 'loop test', as a closed loop path applied in displacement space. More recently, Taiebat \& Carter (2010) and Shen et al. (2017) used a similar approach, called the 'modified swipe test', in which the displacement increment in the first DoF is gradually reduced using a cosine function while the displacement increment in the other DoF is gradually increased using a sine function. Taiebat \& Carter (2010) suggested that this would maintain a greater plastic displacement than the elastic displacement in the first DoF while the plastic displacements were developing in the other DoF, which would maintain normality over the whole load path and, thus, the load path would stay on the failure envelope.

Regardless of the different names adopted (loop test, modified swipe test, sequential swipe test), the key principle behind these tests is the same, which is that changes in displacement direction should be applied gradually. Fig. 2(b) shows the different load paths taken by representative displacement probe and sequential swipe tests. The sequential swipe test can be considered as a 'discrete' version of the loop or modified swipe test, in which the user can control how gradually the displacement direction changes through the number of discrete swipe stages (denoted below as $m$ ). This will be made clearer in the following exposition.

Suppose that the directional change in the displacement space is controlled by $\psi$, the angle between the current and previous increments in displacement space. In this paper, the sequential swipe test is implemented by keeping $\psi$ constant between all stages of the swipe sequence. For example, a two-swipe sequential swipe test in the first quadrant of $w-u$ displacement space (assuming the initial pre-swipe displacement is in the $w$ direction) applies $\psi=\pi / 4$ for all swipes, resulting in $\delta u / \delta w=\tan (\pi / 4)$ followed by $\delta u / \delta w=\tan (\pi / 2)$, where $\delta u$ and $\delta w$ are the horizontal and vertical displacement increments respectively. Correspondingly, an $m$-swipe sequential swipe test in the same displacement space applies $\psi=\pi / 2 m$ for all swipes, where the direction of the displacement increment in the $i$ th swipe is given in equation (1). Here $q_{1}$ and $q_{2}$ denote generic normalised displacements 


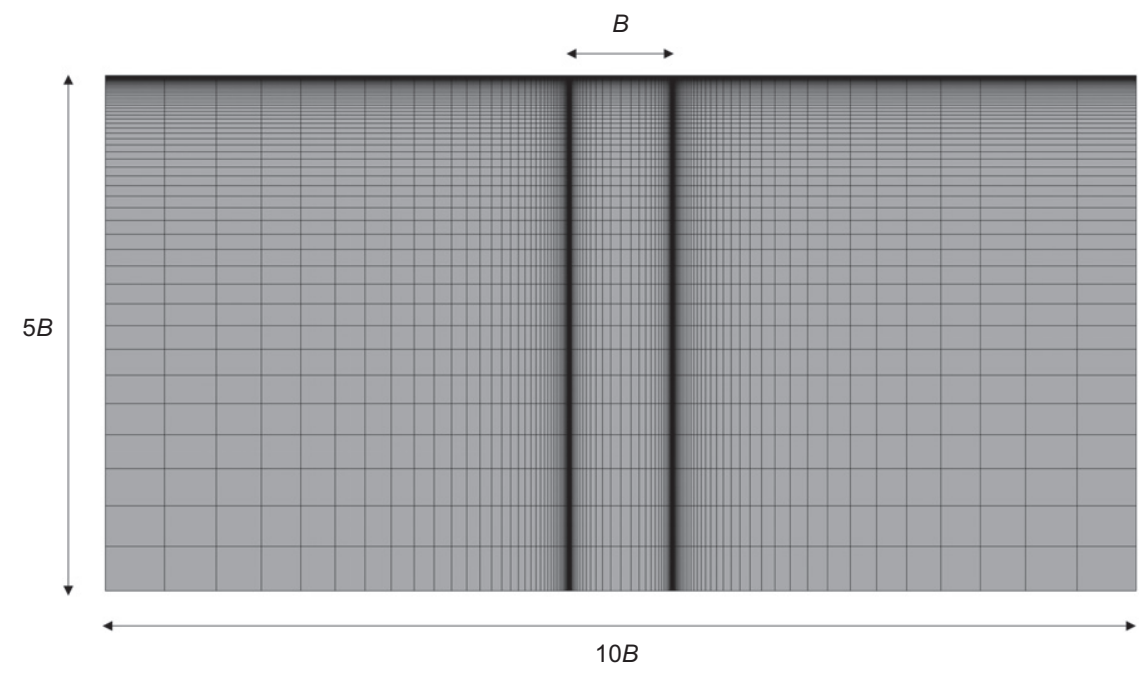

Fig. 3. FEA mesh for sequential swipe testing of a surface strip foundation of width $B$ (domain: $5 B$ in depth and $10 B$ in width)

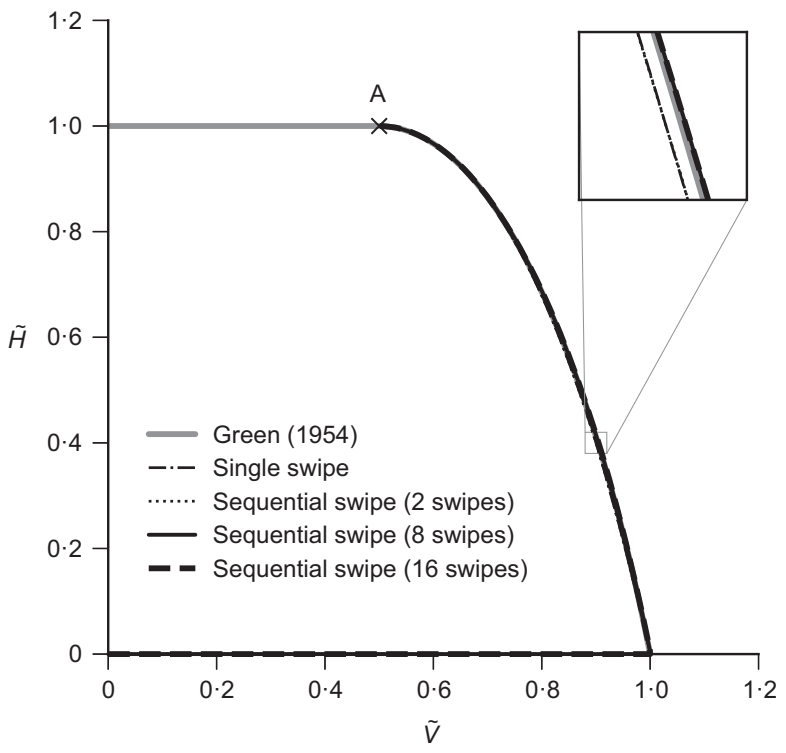

(a)

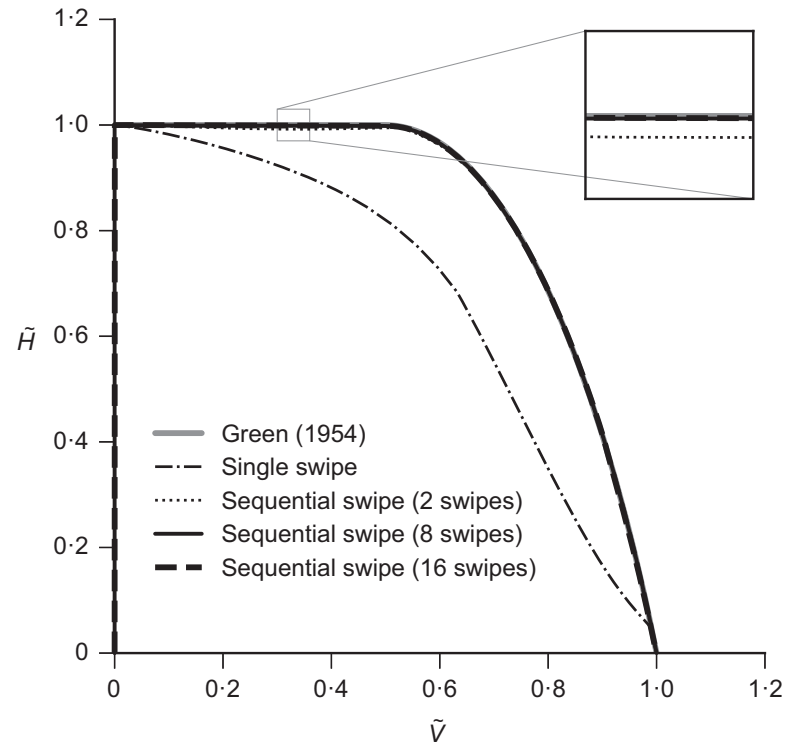

(b)

Fig. 4. Comparison of various swipe tests in $V H$ load space with the analytical solution of Green (1954): (a) swipe tests first reach maximum $V$ capacity before swiping to maximum $H$ capacity; (b) swipe tests first reach maximum $H$ capacity before swiping to maximum $V$ capacity

corresponding to the first and second DoF, respectively, while $\psi_{\mathrm{t}}$ is the total directional change in the displacement space during the swipe phase (e.g. $q_{1}=w / D, q_{2}=u / D$ and $\psi_{\mathrm{t}}=\pi / 2$ for the above swipe).

$$
\left(\frac{\delta q_{2}}{\delta q_{1}}\right)_{i}=\tan \left(\frac{i \psi_{\mathrm{t}}}{m}\right) \quad \text { for } 1 \leq i \leq m
$$

The larger $m$ is, the more gradually the displacement direction changes. A single swipe test can be obtained as a special case of the sequential swipe test by letting $m=1$. As a preliminary investigation to illustrate the effect of $m$, different $m$-valued sequential swipe tests were carried out for a surface strip foundation on von Mises soil.

Figure 3 shows the two-dimensional (2D) FEA mesh for the surface strip foundation, which consists of 7200 secondorder, fully integrated, hybrid quadrilateral elements (Abaqus code $\mathrm{CPE} 8 \mathrm{H}$ ). The von Mises yield strength in pure shear, $k$, was equated with the undrained shear strength of the clay, $s_{\mathrm{u}}$, and was modelled as homogeneous throughout the soil domain. The Poisson's ratio of the soil, $v$, was set as $0 \cdot 49$, while its Young's modulus, $E$, was set as $1000 \sqrt{3} s_{\mathrm{u}}$. The soil was modelled as a weightless material, as soil weight does not affect the capacity for this type of problem (i.e. horizontal ground surface; pressure-insensitive von Mises yield criterion for the soil; no contact breaking between foundation and soil). The surface strip foundation was modelled indirectly by applying a rigid body constraint to the soil nodes underneath the foundation.

Figure 4 compares the $V H$ failure envelopes obtained from different $m$-valued sequential swipe tests with the analytical solution (Green, 1954). Two types of swipe analysis were carried out, with one reaching $V_{0}$ before swiping to $H_{0}$ and the other taking the opposite route. For each analysis, three sequential swipe tests were carried out, with $m$ ranging from 2 to 16. Key observations from Fig. 4 are listed below.

(a) All the tests swiping to $H_{0}$ end at point A, where the analytical solution indicates no further change in failure envelope gradient, as shown in Fig. 4(a). 
(b) The single swipe test marginally under-predicts the failure envelope in Fig. 4(a) but significantly under-predicts it in Fig. 4(b). In contrast, the sequential swipe tests show accurate tracking of the failure envelope, regardless of the starting point of the swipe phase.

(c) It can be observed that the load paths of the sequential swipe tests are essentially indistinguishable from the analytical failure envelope when $m \geq 8$. This suggests that if $m$ is above some critical value, the load path will track the failure envelope with negligible deviation.

When completing the analyses for Fig. 4, it was observed that the rate of increase in the total computational time decreased as the number of discrete swipe stages increased (this is because the FEA requires fewer incrementation cutbacks and equilibrium iterations for smaller $\psi$ than for larger $\psi$ ). For example, the total additional computational times (relative to the single swipe test) taken by the two-swipe, eight-swipe and 16-swipe tests were approximately $19 \%, 24 \%$ and $28 \%$, respectively. This indicates a marginal penalty in choosing a higher number of stages for the sequential swipe test. Hence, it is more practical to select a high number of stages at the outset (e.g. $m=8$ ) than to waste computational resources attempting to find the optimal $m$, which in any case is likely to vary with the problem type and the current load state.

For more systematic mapping of high-dimensional $(n \geq 3)$ failure envelopes, it is advisable that the sequential swipe test is restricted to two dimensions, while constant load conditions are applied for the other dimensions. In other words, for a failure envelope with dimensionality $n \geq 3$, the sequential swipe test should be used primarily to find $2 \mathrm{D}$ contours of the failure envelope.

\section{APPLICATION OF NUMERICAL PROCEDURES}

To further evaluate the numerical procedures described above, each procedure was used to find the failure envelopes for planar VHM loading of two types of shallow foundation (circular surface and suction caisson foundations) bearing on undrained clay.

\section{Foundation and soil properties}

Both the surface and caisson foundations were modelled as fully rigid, with a diameter $D$. The caisson foundation was modelled as having an embedded length $L=D$ and a skirt of thickness $t_{\mathrm{s}}=0 \cdot 005 \mathrm{D}$. The undrained clay was modelled in FEA as a homogeneous, linear elastic $(v=0 \cdot 49$;
$E=1000 \sqrt{ } 3 s_{\mathrm{u}}$ ), perfectly plastic material and in FELA as a homogeneous, rigid, perfectly plastic material. For both sets of analyses, the von Mises yield criterion (with a yield strength in pure shear of $s_{\mathrm{u}}$ ) and an associated flow rule were adopted. The soil and foundations were modelled as weightless materials, as soil weight does not affect the capacity for the problems considered here (for the same reasons as described above).

\section{The 3D FEA model}

First-order, fully integrated, hybrid brick elements (Abaqus code $\mathrm{C} 3 \mathrm{D} 8 \mathrm{H}$ ) were used for the soil as these are generally recommended for modelling near-incompressible materials (Dassault Systèmes, 2014). Brick elements were also used for the foundation, but the foundation was made fully rigid by the application of a rigid body constraint. Sliding and contact breaking between the foundation and soil were not allowed.

Figure 5 shows the 3D FEA meshes for the surface and caisson foundations, with symmetry exploited. Displacement boundary conditions were set to prevent radial displacements on the circumferential faces and out-of-plane displacements on the plane of symmetry. In addition, the base of the mesh was fixed in all directions. The meshes were sufficiently large that boundary effects on the failure response of the foundation were verified to be negligible. The meshes for the surface and caisson foundations comprised approximately 40000 and 44000 elements, respectively.

\section{The 3D FELA model}

The FELA software OxLim first discretises the soil domain into a mesh of tetrahedral elements using TetGen (Si, 2015) and applies the boundary conditions. It then sets up two constrained optimisation problems that together bound the load multiplier (i.e. the factor by which the specified live loads must be increased to cause failure). For this study, the lower-bound (LB) analyses used a piecewise linear stress field, and the upper-bound (UB) analyses used a piecewise linear velocity field. The average of the bounds, $(\mathrm{LB}+\mathrm{UB}) / 2$, was taken as the best estimate solution for the load multiplier. The use of the von Mises criterion meant that both the LB and UB analyses could be cast as standard second-order cone programming problems and solved with high efficiency using specialised numerical optimisation software (Mosek, 2014).

OxLim uses adaptive mesh refinement to improve the bracketing of the exact collapse load multiplier, where the

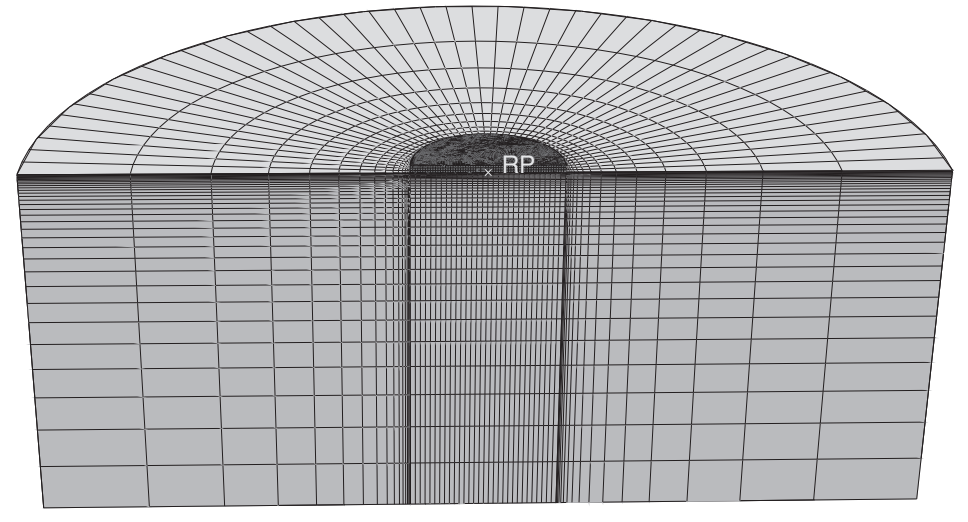

(a)

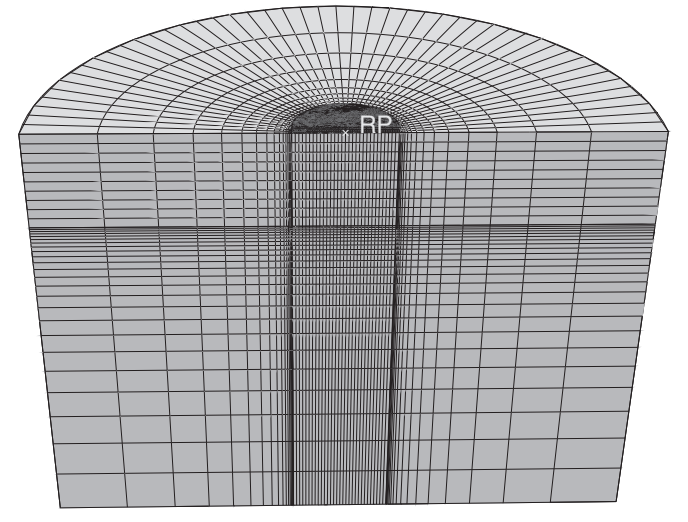

(b)

Fig. 5. FEA meshes for displacement probe and swipe tests: (a) surface foundation of diameter $D$ (domain: $2 \cdot 5 D$ in depth and $3 D$ in radius); (b) caisson foundation of diameter $D$ and skirt length $L=D$ (domain: $4 \cdot 5 D$ in depth and $3 D$ in radius) 


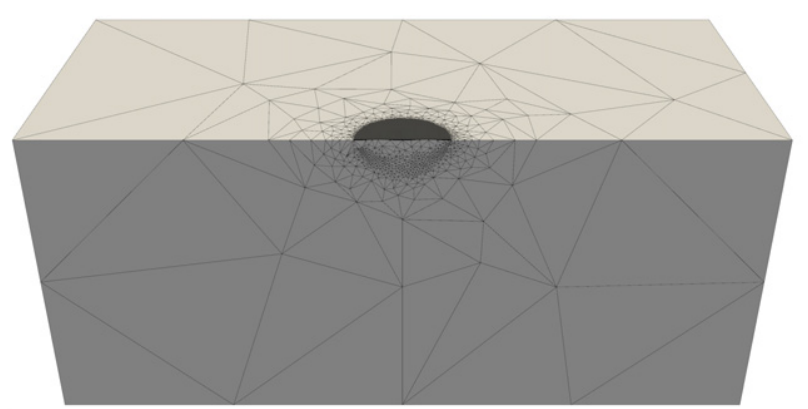

(a)



(b)

Fig. 6. FELA meshes for load probe tests. For surface foundation of diameter $D$, mesh domain is $3 \cdot 5 D$ deep, $7 D$ wide and $3 \cdot 5 D$ thick. For caisson foundation of diameter $D$ and skirt length $L=D$, mesh domain is $4 \cdot 5 \mathrm{D}$ deep, $9 \mathrm{D}$ wide and $4 \cdot 5 \mathrm{D}$ thick. (a) Surface foundation, refined mesh under moment loading; (b) caisson foundation, refined mesh under moment loading

adaptivity is based on the spatial variation of the deviatoric strain rate in the UB velocity field. For the surface foundation, the initial mesh was adaptively refined twice to increase the number of elements from approximately 6500 to 25 000, as shown in Fig. 6(a). For the caisson foundation, the initial mesh was adaptively refined once to increase the number of elements from approximately 14000 to 30000 , as shown in Fig. 6(b). To keep the number of elements comparable with the FEA mesh, a second refinement was not undertaken for the caisson foundation. It should be noted, however, that the average of the LB and UB solutions (which is the main measure of comparison with the FEA results) typically does not vary significantly as the bounds converge. The mesh domain was sufficiently large to render boundary effects negligible. Fixed boundary conditions were applied to the base and sides of the domain (excluding the symmetric plane).

\section{Loading methodology}

For this study, the failure envelopes were explored in increasing dimensionality of load components. First, the uniaxial capacities were identified for pure $V, H$ and $M$ loading. Thereafter, failure envelopes for combined $V H, V M$ and $H M$ loading were found. Owing to the symmetry in the $V H$ and $V M$ load spaces, only one quadrant of the failure envelope needs to be determined. Similarly, symmetry in the $H M$ load space dictates that only two adjoining quadrants are needed to define the full failure envelope.

For the displacement probe tests, nine equally spaced displacement probe directions were used in each quadrant. For comparison purposes, eight discrete swipe stages (using the same set of probe directions) were adopted for the sequential swipe tests. The displacement probe directions can be identified from equation (1) by letting $\delta q_{1}$ and $\delta q_{2}$ be the
Table 1. Uniaxial capacities of surface and caisson foundations

\begin{tabular}{|c|c|c|c|}
\hline & $\frac{V_{0}}{A s_{\mathrm{u}}}$ & $\frac{H_{0}}{A s_{\mathrm{u}}}$ & $\frac{M_{0}}{A D s_{\mathrm{u}}}$ \\
\hline \multicolumn{4}{|l|}{ Surface } \\
\hline Displacement probe & $5 \cdot 63$ & $1 \cdot 02$ & $0 \cdot 714$ \\
\hline Load probe (LB) & $5 \cdot 45$ & $1 \cdot 00$ & 0.667 \\
\hline Load probe (UB) & $5 \cdot 77$ & $1 \cdot 00$ & $0 \cdot 715$ \\
\hline Load probe (average) & $5 \cdot 61$ & $1 \cdot 00$ & 0.691 \\
\hline \multicolumn{4}{|l|}{ Caisson } \\
\hline Displacement probe & $13 \cdot 12$ & $5 \cdot 86$ & $3 \cdot 64$ \\
\hline Load probe (LB) & $12 \cdot 52$ & $5 \cdot 52$ & $3 \cdot 36$ \\
\hline Load probe (UB) & $13 \cdot 68$ & $6 \cdot 28$ & $3 \cdot 96$ \\
\hline Load probe (average) & $13 \cdot 10$ & $5 \cdot 90$ & $3 \cdot 66$ \\
\hline
\end{tabular}

$A=\pi D^{2} / 4$ refers to the foundation plan area. Note that the procedure and results for the displacement probe, single swipe and sequential swipe tests are identical for uniaxial loading.

normalised displacement/rotation increments corresponding to the load components (e.g. in the $H M$ load space, $q_{1}=u / D$ and $q_{2}=\theta$ ). Thereafter, let $m=8$ and $\psi_{\mathrm{t}}=\pi / 2$ (for $V H$ and $V M$ ) or $m=16$ and $\psi_{\mathrm{t}}=\pi$ (for $H M$ ). Single swipe tests were also implemented for the study, with the probe directions similarly identified from equation (1) by letting $m=1$ and $\psi_{\mathrm{t}}=\pi / 2$ (for $V H$ and $V M$ ) or $m=2$ and $\psi_{\mathrm{t}}=\pi$ (for $H M$ ). With regard to the magnitude of the displacement increments used in the displacement probe, sequential swipe or single swipe tests, they were chosen to be sufficiently large for the load to reach steady state by the end of each displacement increment. For this study, the magnitude of each normalised displacement increment (i.e. $\sqrt{\delta q_{1}^{2}+\delta q_{2}^{2}}$ ) was set at a constant value of $0 \cdot 1$. For the load probe tests, nine equally spaced loading directions were used in each quadrant.

Finally, the full VHM failure envelope was determined. Mixed load and displacement controls were used for the FEA-based tests. Load control was used for $V$, while displacement control was used in the $H M$ load space - that is, the $V H M$ failure envelope was explored by determining $H M$ contours of the failure envelope at fixed levels of $V$. Five vertical load levels were considered: $\tilde{V}=0 \cdot 25,0 \cdot 5,0 \cdot 625,0 \cdot 75$ and 0.875 . A similar procedure was followed for the load probe tests performed using FELA, with the $H M$ contours being determined by probing in $H M$ load space under the same set of fixed $V$ loads.

\section{RESULTS}

\section{Pure V, $\mathrm{H}$ and $\mathrm{M}$ loading}

To validate whether the FEA- and FELA-based procedures would provide similar answers for the same problems, Table 1 compares the results obtained by the various procedures for the uniaxial foundation capacities $\left(V_{0}, H_{0}\right.$ and $M_{0}$ ), which shows that the results from the displacement probes using FEA are within the bounds obtained using the 3D FELA procedure, except for $H_{0}$ for the surface foundation. Furthermore, the FELA load probe (average) results generally agree very well with the FEA-based results.

\section{Combined VH, VM and HM loading}

Figures 7-9 show the $V H, V M$ and $H M$ failure envelopes for both foundations. Because of symmetry, only one or two quadrants are shown in these figures, as appropriate. The small black markers in Figs 7-9 for the sequential swipe test results represent intermediate equilibrium load states during each discrete stage of the sequential swipe, which are determined by Abaqus's automatic step size incrementation 


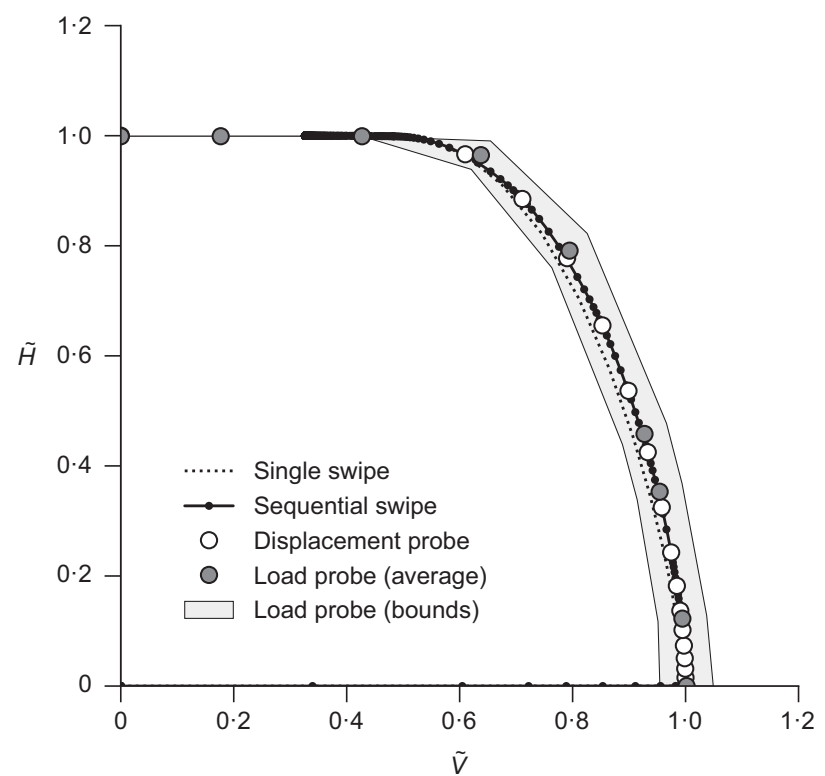

(a)

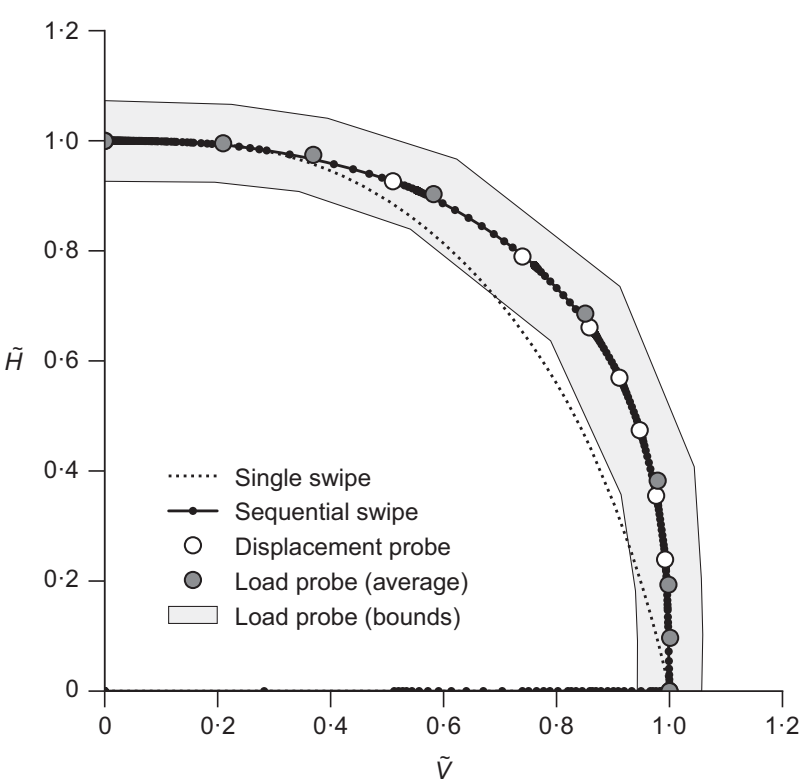

(b)

Fig. 7. Dimensionless $V H$ failure envelopes: (a) surface foundation; (b) caisson foundation



(a)



(b)

Fig. 8. Dimensionless $V M$ failure envelopes: (a) surface foundation; (b) caisson foundation



(a)

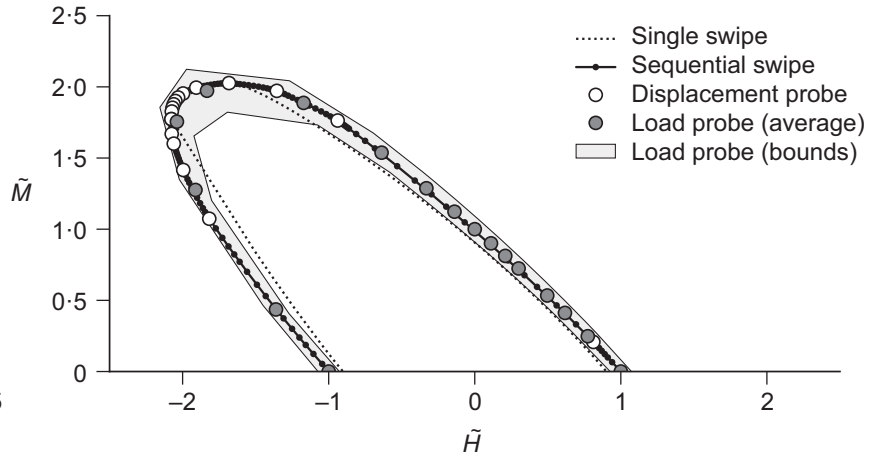

(b)

Fig. 9. Dimensionless $H M$ failure envelopes: (a) surface foundation; (b) caisson foundation 
scheme. The density of the black markers (i.e. the resolution of the failure envelope) can be controlled by changing the step size incrementation scheme. The final load states from the displacement probe tests, and the load paths from the sequential swipe tests, were all within the bounds obtained from the load probe tests. In fact, there are no significant differences between these two sets of FEA-generated results and the FELA load probe (average) results. In contrast, there is noticeable under-prediction of the failure envelopes by the single swipe test. The underprediction of the failure envelopes for the surface foundation is minor for most cases, except for the $H M$ failure envelope when $\tilde{H} \geq 0 \cdot 7$. However, under-prediction of the failure envelopes for the caisson foundation is apparent for all the load spaces explored.

\section{Combined VHM loading}

Figure 10 shows the $H M$ failure envelopes obtained for both foundations under three selected levels of normalised vertical load $\tilde{V}$. Again, the results of the displacement probe and sequential swipe tests are all within the LB and UB envelopes obtained using FELA. Furthermore, Fig. 11 shows the $H M$ failure envelopes obtained from both the
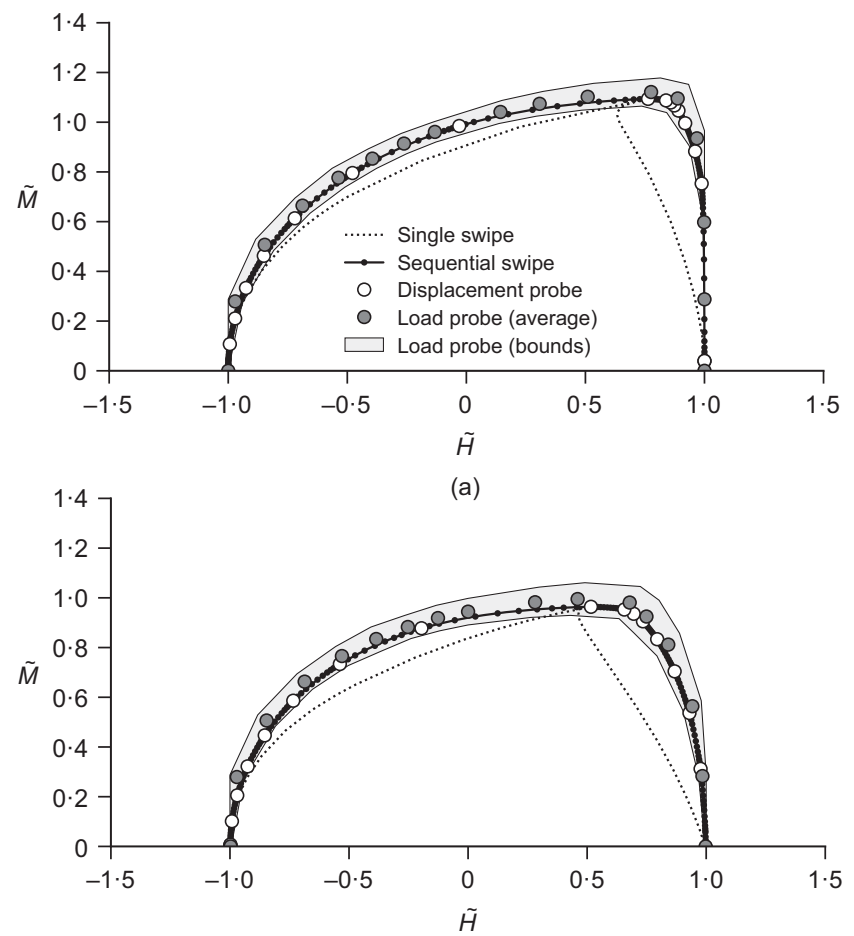

(b)

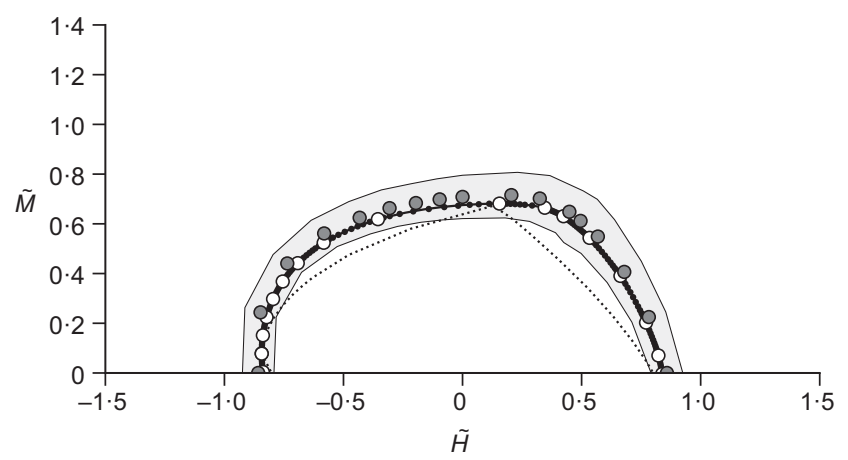

(c) single swipe and sequential swipe tests, for all of the vertical load levels considered. It is evident that the single swipe test under-predicts the $H M$ failure envelopes for all vertical load levels.

\section{DISCUSSION}

To assess the performance of the various numerical procedures in determining the above failure envelopes, the following performance criteria were adopted: accuracy, computational efficiency and resolution.

To allow for a quantitative (albeit approximate) comparison of the accuracy of the various numerical procedures, an accuracy measure $\eta$ (relative to the displacement probe test) is introduced as follows

$$
\eta=\frac{A_{i}}{A_{\text {ref }}}
$$

where $A_{i}$ refers to the area enclosed within a failure envelope that was determined by any numerical procedure, and $A_{\text {ref }}$ refers to the area enclosed within a reference failure envelope that was determined by the displacement probe method (which is the most widely used among the FEA-based procedures). The area calculations were performed by



(d)

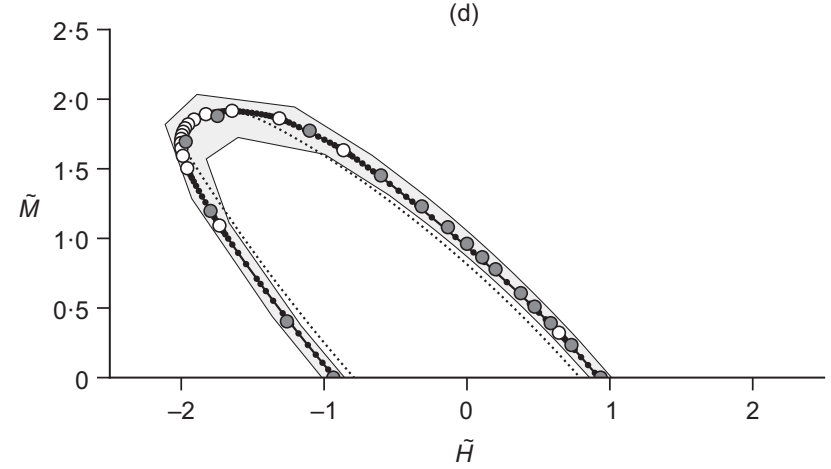

(e)

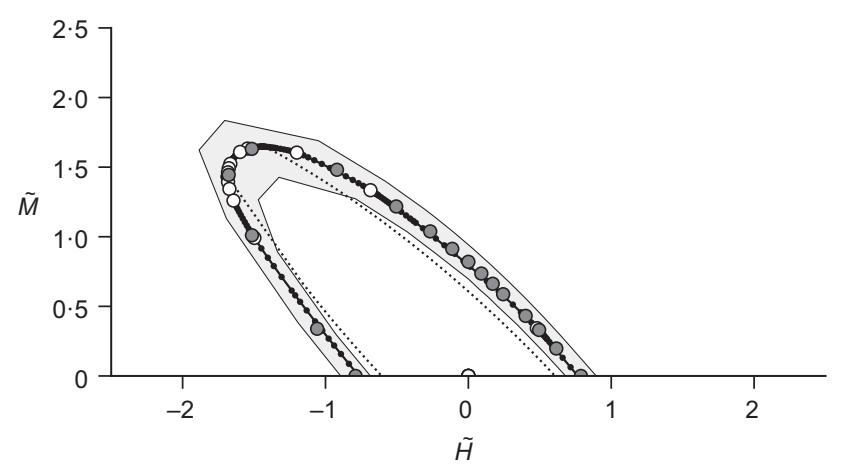

(f)

Fig. 10. Dimensionless $H M$ failure envelopes at selected $\tilde{V}$ levels for surface foundations: (a) $\tilde{V}=0 \cdot 25$; (b) $\tilde{V}=0 \cdot 5$; (c) $\tilde{V}=0 \cdot 75$; and caisson foundations: (d) $\tilde{V}=0.25$; (e) $\tilde{V}=0.5$; (f) $V=0.75$ 




(a)

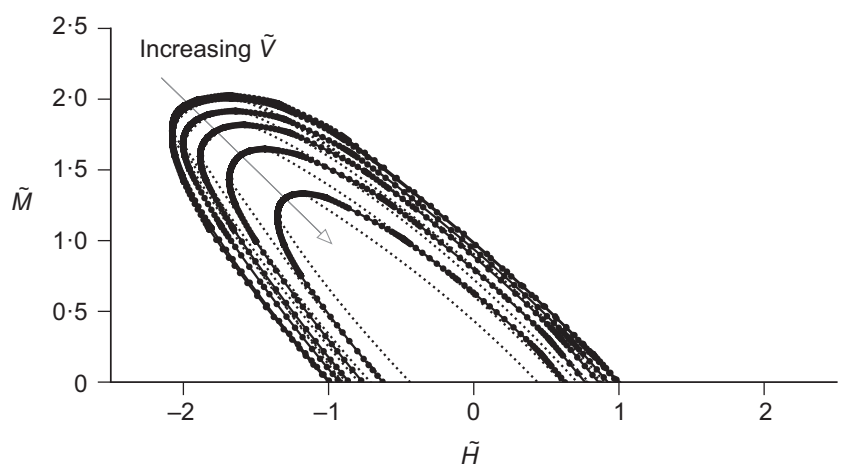

(b)

Fig. 11. Dimensionless $H M$ failure envelopes at selected $\tilde{V}$ levels $(\tilde{V}=0,0 \cdot 25,0 \cdot 5,0 \cdot 625,0 \cdot 75,0 \cdot 85)$ : (a) surface foundation; (b) caisson foundation

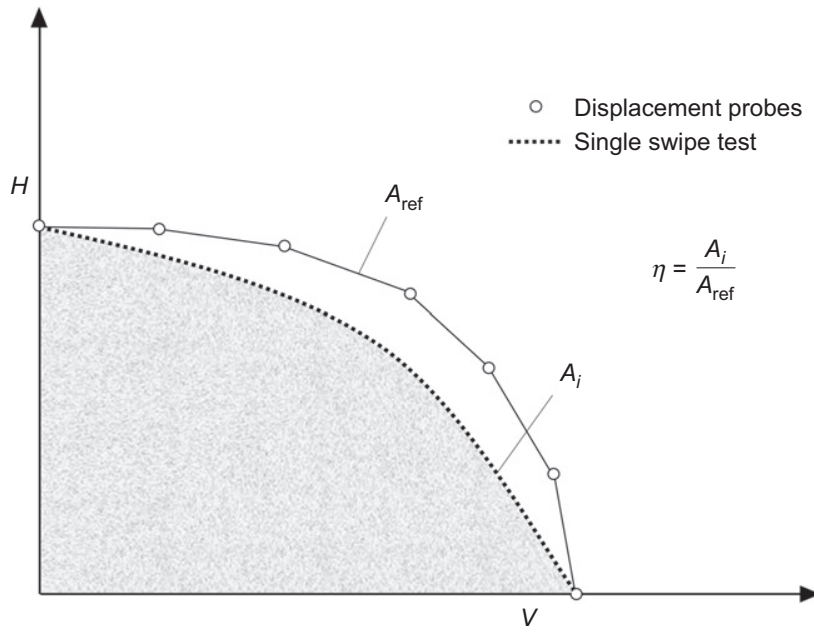

Fig. 12. Computation of the accuracy measure $\eta$ for a typical single swipe test in $V H$ space, where $A_{i}$ is the area enclosed by the failure envelope from the single swipe test (i.e. the shaded area) and $A_{\text {ref }}$ is the area enclosed by the failure envelope from the displacement probe tests

taking the set of failure points as the vertices of a polygon (the failure points are taken to be the average of the bounds for the FELA analyses). Fig. 12 shows an illustration of a typical computation of the accuracy measure $\eta$. Note that values of $\eta$ above 1 do not necessarily imply inaccuracy, as some of the procedures have either a higher number of failure points (e.g. single swipe and sequential swipe tests) or more evenly spaced failure points (e.g. load probe test) to better approximate the computation of the failure envelope area.

Table 2 shows the comparison of $\eta$ for each numerical procedure, for each failure envelope shown in Figs 7-10. It can be observed that the sequential swipe test and the load probe test provide similar levels of accuracy to the displacement probe test, with $\eta$ ranging from 1.01 to 1.03 and 1.01 to $1 \cdot 07$, respectively. The single swipe test, however, generally under-predicts the failure envelope areas, with $\eta$ ranging from 0.78 to $1 \cdot 01$. On average (and relative to the displacement probe test results), the single swipe test under-predicts the reference failure envelopes by $11 \%$, while the sequential swipe test and load probe test over-predict the reference failure envelopes by $2 \%$ and $3 \%$, respectively.

Table 3 shows the total and average (per probe) computational time taken by each procedure to find the $V H, V M, H M$ and $V H M$ failure envelopes presented in the previous section. Using FEA, 120 displacement probe tests were performed for each foundation. For the sequential swipe tests, the same 120 probe directions were used for the discrete
Table 2. Comparison of the accuracy measure $\eta$ (as per equation (2)) for the surface and caisson foundations, for each failure envelope shown in Figs 7-10

\begin{tabular}{l|c|c|c}
\hline $\begin{array}{l}\text { Failure } \\
\text { envelope }\end{array}$ & $\begin{array}{c}\eta \text { (single } \\
\text { swipe) }\end{array}$ & $\begin{array}{c}\eta \text { (sequential } \\
\text { swipe) }\end{array}$ & $\begin{array}{c}\eta \text { (load } \\
\text { probe) }\end{array}$ \\
\hline Surface & \multicolumn{3}{|c}{} \\
$\quad$ Figure 7(a) & 0.99 & 1.01 & 1.01 \\
Figure 8(a) & 1.01 & 1.03 & 1.04 \\
Figure 9(a) & 0.89 & 1.01 & 1.03 \\
Figure 10(a) & 0.87 & 1.01 & 1.04 \\
Figure 10(b) & 0.83 & 1.01 & 1.05 \\
Figure 10(c) & 0.81 & 1.01 & 1.07 \\
Caisson & & & \\
Figure 7(b) & 0.92 & 1.01 & 1.01 \\
Figure 8(b) & 0.94 & 1.03 & 1.02 \\
Figure 9(b) & 0.88 & 1.04 & 1.00 \\
Figure 10(d) & 0.90 & 1.04 & 1.01 \\
Figure 10(e) & 0.87 & 1.04 & 1.02 \\
Figure 10(f) & 0.78 & 1.04 & 1.04 \\
Average & 0.89 & 1.02 & 1.03 \\
\hline
\end{tabular}

Table 3. Computational time taken by each numerical procedure to find all failure envelopes $(V H, V M, H M, V H M)$ of the surface and caisson foundations

\begin{tabular}{|c|c|c|c|}
\hline & $\begin{array}{l}\text { Number } \\
\text { of probes }\end{array}$ & $\begin{array}{l}\text { Total } \\
\text { time: } \mathrm{h}\end{array}$ & $\begin{array}{l}\text { Average time } \\
\text { per probe: } h\end{array}$ \\
\hline \multicolumn{4}{|l|}{ Surface } \\
\hline Displacement probe & 120 & $68 \cdot 6$ & $0 \cdot 571$ \\
\hline Single swipe & 22 & $21 \cdot 4$ & 0.971 \\
\hline Sequential swipe & 120 & $25 \cdot 5$ & $0 \cdot 212$ \\
\hline Load probe & 120 & $31 \cdot 2$ & $0 \cdot 260$ \\
\hline \multicolumn{4}{|l|}{ Caisson } \\
\hline Displacement probe & 120 & $152 \cdot 8$ & $1 \cdot 27$ \\
\hline Single swipe & 22 & $23 \cdot 0$ & 1.05 \\
\hline Sequential swipe & 120 & $59 \cdot 5$ & $0 \cdot 496$ \\
\hline Load probe & 120 & $22 \cdot 3$ & $0 \cdot 186$ \\
\hline
\end{tabular}

swipe stages. In contrast, only 22 displacement increments (corresponding to the first and last probe directions in each quadrant of the displacement space) were performed for the single swipe tests. Using FELA, 120 load probe tests were performed to identify 120 failure loads. All the analyses were set up using scripts and the difference in set-up time is thus negligible. The computer used to run the analyses had an Intel Xeon $3.60 \mathrm{GHz}$ processor (eight central processing units) with 16 GB RAM (random access memory).

Table 3 is revealing in several ways. The single swipe test was found to be the most efficient procedure if the total time 
taken is adopted as the efficiency measure. However, different procedures provide different numbers of reliable failure points; only the final failure points which have reached steady state at the end of each probe are dependably accurate for all cases. Thus, an alternative efficiency measure, the time taken per reliable failure point (defined as the average time to analyse one probe), was compared. Based on this efficiency measure, the load probe test was found to be the most efficient procedure. For the analyses of the surface and caisson foundations, the sequential swipe test was, respectively, 2.7 and 2.6 times faster than the displacement probe test. This is an interesting result as it shows the existence of a numerical procedure capable of providing failure envelope predictions that are as accurate as the displacement probe test, but with greater efficiency. The single swipe test, on the other hand, has lower efficiency than the sequential swipe test when evaluated on a per probe basis.

In terms of resolution, the single swipe and sequential swipe tests provide more failure points than the other procedures. However, Figs 7-9 have shown that the load path followed during a single swipe test may be far from the FELA load probe (average) results (and outside the bounds). Thus, the intermediate points during the single swipe test may not be accurate failure points. In contrast, the same figures show that the intermediate points obtained during each stage of a sequential swipe test are sufficiently close to the FELA load probe (average) results (and within the bounds) to be considered as reasonably accurate failure points. Thus, the sequential swipe test provides higher failure envelope resolution than the other procedures.

Overall, the sequential swipe test appears to provide the best balance of accuracy, efficiency and resolution among the FEA-based procedures, while the FELA-based load probe test provides a good balance of accuracy and efficiency (if resolution is not an important criterion). However, if the accuracy of intermediate failure points is not an important criterion, the load path from a single swipe test can provide a quick and conservative estimation of the failure envelope; although users should be aware that the shape of a failure envelope determined from the intermediate points can sometimes be significantly different from the reference failure envelope (e.g. see Figs 4(b) and 11(a)).

There are some limitations of this comparative study. First, the conclusions of this study have only been obtained for von Mises soil. It is unknown whether the same conclusions apply for other soil models such as the Mohr-Coulomb model, especially if a non-associated flow rule is adopted. Second, the influence of features such as non-homogeneous soil strength profiles and the allowance for contact breaking between foundation and soil have not been investigated. Further studies are required to address these issues.

\section{CONCLUSIONS}

The primary goal of this paper was to evaluate the performance of various numerical procedures for determining undrained $V H M$ failure envelopes of shallow foundations: the displacement probe test, the single swipe test and the sequential swipe test (all performed using FEA) as well as the load probe test (performed using FELA). Two circular foundation types with significantly different failure envelope shapes were considered.

In general, there is little to differentiate between the procedures in terms of accuracy, except for the single swipe test, where the load path was sometimes found to underpredict (i.e. deviate inside) the reference failure envelope. For the examples considered in this paper, the sequential swipe test appears to offer the best balance of accuracy, efficiency and resolution. The FELA-based load probe test has higher efficiency but lower resolution. The findings suggest that the sequential swipe test offers an attractive alternative to the widely used displacement probe test, since it is just as accurate, but is faster and has the additional benefit of higher failure envelope resolution.

Finally, this study investigated the influence of the number of discrete swipe stages used in a sequential swipe test. It was found that there is a critical number above which the load path appears to track the failure envelope with negligible deviation. Based on the findings of this paper, a minimum of eight discrete swipe stages in each quadrant of the displacement space is recommended to ensure that the load path stays close to the failure envelope throughout the analysis. As the number of discrete swipe stages decreases, the accuracy of the sequential swipe test decreases and the load path becomes more sensitive to the starting point of the swipe phase, as shown by the single swipe test results in Fig. 4.

\section{ACKNOWLEDGEMENTS}

The first and second authors acknowledge the generous support of Ørsted Wind Power and Subsea 7, respectively, for funding their DPhil studentships at the University of Oxford.

\section{NOTATION}

$A_{i} \quad$ area enclosed by failure envelope from any numerical procedure

$A_{\text {ref }}$ area enclosed by reference failure envelope from displacement probe tests

$B$ width of surface strip foundation

$H$ horizontal load

$\tilde{H}$ normalised horizontal load

$H_{0}$ horizontal uniaxial capacity

$M$ moment load

$\tilde{M}$ normalised moment load

$M_{0} \quad$ moment uniaxial capacity

$m$ number of discrete sequential swipe stages

$n$ number of loading dimensions

$q_{1}$ normalised generalised first degree of freedom

$q_{2}$ normalised generalised second degree of freedom

$u$ horizontal displacement

$V$ vertical load

$\tilde{V}$ normalised vertical load

$V_{0} \quad$ vertical uniaxial capacity

$w \quad$ vertical displacement

$\eta$ relative accuracy measure for failure envelopes

$\theta$ rotational displacement

\section{REFERENCES}

Bell, R. W. (1991). The analysis of offshore foundations subjected to combined loading. MSc thesis, University of Oxford, Oxford, UK.

Bransby, M. F. \& Randolph, M. F. (1998). Combined loading of skirted foundations. Géotechnique 48, No. 5, 637-655, https://doi.org/10.1680/geot.1998.48.5.637.

Bransby, M. F. \& Yun, G. J. (2009). The undrained capacity of skirted strip foundations under combined loading. Géotechnique 59, No. 2, 115-125, https://doi.org/10.1680/geot.2007.00098.

Byrne, B. W. (2000). Investigations of suction caissons in dense sand. DPhil thesis, University of Oxford, Oxford, UK.

Cassidy, M. J., Byrne, B. W. \& Randolph, M. F. (2004). A comparison of the combined load behaviour of spudcan and caisson foundations on soft normally consolidated clay. Géotechnique 54, No. 2, 91-106, https://doi.org/10.1680/geot. 2004.54.2.91.

Dassault Systèmes (2014). Abaqus user manual, version 6.13. Providence, RI, USA: Simulia Corp.

Dunne, H. P. \& Martin, C. M. (2017). Capacity of rectangular mudmat foundations on clay under combined loading. Géotechnique 67, No. 2, 168-180, https://doi.org/10.1680/jgeot. 16.P.079. 
Dunne, H. P., Martin, C. M., Muir, L., Brown, N. \& Wallerand, R. (2015). Undrained bearing capacity of skirted mudmats on inclined seabeds. In Frontiers in Offshore Geotechnics III (ed. V. Meyer), pp. 783-788. Boca Raton, FL, USA: CRC Press.

Feng, X., Randolph, M. F., Gourvenec, S. \& Wallerand, R. (2014). Design approach for rectangular mudmats under fully three-dimensional loading. Géotechnique 64, No. 1, 51-63, https://doi.org/10.1680/geot.13.P.051.

Fu, D., Bienen, B., Gaudin, C. \& Cassidy, M. J. (2014). Undrained capacity of a hybrid subsea skirted mat with caissons under combined loading. Can. Geotech. J. 51, No. 8, 934-949.

Gerolymos, N., Zafeirakos, A. \& Karapiperis, K. (2015). Generalized failure envelope for caisson foundations in cohesive soil: static and dynamic loading. Soil Dynamics Earthquake Engng 78, 154-174.

Gottardi, G. \& Butterfield, R. (1993). On the bearing capacity of surface footings on sand under general planar loads. Soils Found. 33, No. 3, 68-79.

Gottardi, G., Houlsby, G. T. \& Butterfield, R. (1999). Plastic response of circular footings on sand under general planar loading. Géotechnique 49, No. 4, 453-469, https://doi.org/ 10.1680/geot.1999.49.4.453.

Gourvenec, S. (2007). Failure envelopes for offshore shallow foundations under general loading. Géotechnique 57, No. 9, 715-728, https://doi.org/10.1680/geot.2007.57.9.715.

Gourvenec, S. \& Barnett, S. (2011). Undrained failure envelope for skirted foundations under general loading. Géotechnique 61, No. 3, 263-270, https://doi.org/10.1680/geot.9.T.027.

Gourvenec, S. \& Randolph, M. F. (2003). Effect of strength nonhomogeneity on the shape of failure envelopes for combined loading of strip and circular foundations on clay. Géotechnique 53, No. 6, 575-586, https://doi.org/10.1680/geot.2003.53.6.575.

Gourvenec, S., Randolph, M. \& Kingsnorth, O. (2006). Undrained bearing capacity of square and rectangular footings. Int. J. Geomech. 6, No. 3, 147-157.

Green, A. P. (1954). The plastic yielding of metal junctions due to combined shear and pressure. J. Mech. Phys. Solids 2, No. 3, 197-211.

Houlsby, G. T. \& Byrne, B. W. (2001). Discussion: Comparison of European bearing capacity calculation methods for shallow foundations. Proc. Instn Civ. Engrs - Geotech. Engng 149, No. 1, 63-64, https://doi.org/10.1680/geng.2001.149.1.63.

Hung, L. C. \& Kim, S. R. (2014). Evaluation of undrained bearing capacities of bucket foundations under combined loads. Mar. Georesour. Geotechnol. 32, No. 1, 76-92.

Karapiperis, K. \& Gerolymos, N. (2014). Combined loading of caisson foundations in cohesive soil: finite element versus Winkler modeling. Comput. Geotech. 56, 100-120.

Makrodimopoulos, A. \& Martin, C. M. (2006). Lower bound limit analysis of cohesive-frictional materials using second-order cone programming. Int. J. Numer. Methods Engng 66, No. 4, 604-634.

Makrodimopoulos, A. \& Martin, C. M. (2007). Upper bound limit analysis using simplex strain elements and second-order cone programming. Int. J. Numer. Analyt. Methods Geomech. 31, No. 6, 835-865.

Mana, D. S., Gourvenec, S. \& Martin, C. M. (2013). Critical skirt spacing for shallow foundations under general loading. J. Geotech. Geoenviron. Engng 139, No. 9, 1554-1566.

Martin, C. M. (1994). Physical and numerical modelling of offshore foundations under combined loads. DPhil thesis, University of Oxford, Oxford, UK.

Martin, C. M. (2011). The use of adaptive finite-element limit analysis to reveal slip-line fields. Géotechnique Lett. 1, No. 2, 23-29, https://doi.org/10.1680/geolett.11.00018.
Martin, C. M. \& Houlsby, G. T. (2000). Combined loading of spudcan foundations on clay: laboratory tests. Géotechnique $\mathbf{5 0}$, No. 4, 325-338, https://doi.org/10.1680/geot.2000.50.4.325.

Martin, C. M. \& Houlsby, G. T. (2001). Combined loading of spudcan foundations on clay: numerical modelling. Géotechnique 51, No. 8, 687-699, https://doi.org/10.1680/geot. 2001.51.8.687.

Martin, C. M. \& White, D. J. (2012). Limit analysis of the undrained bearing capacity of offshore pipelines. Géotechnique 62, No. 9, 847-863, https://doi.org/10.1680/geot.12.OG.016.

Mehravar, M., Harireche, O. \& Faramarzi, A. (2016). Evaluation of undrained failure envelopes of caisson foundations under combined loading. Appl. Ocean Res. 59, 129-137.

Meyerhof, G. G. (1951). The ultimate bearing capacity of foundations. Géotechnique 2, No. 4, 301-332, https://doi.org/10. 1680/geot.1951.2.4.301.

Mosek (2014). The MOSEK C optimizer API manual, Version 7.1. Copenhagen, Denmark: MOSEK ApS.

Nouri, H., Biscontin, G. \& Aubeny, C. P. (2014). Undrained sliding resistance of shallow foundations subject to torsion. J. Geotech. Geoenviron. Engng 140, No. 8, 04014042.

Nova, R. \& Montrasio, L. (1991). Settlements of shallow foundations on sand. Géotechnique 41, No. 2, 243-256, https://doi.org/10.1680/geot.1991.41.2.243.

Roscoe, K. \& Schofield, A. N. (1957). The stability of short pier foundations in sand. Br. Weld. J. 4, No. 1, 12-18.

Schotman, G. J. M. (1989). The effects of displacements on the stability of jackup spud-can foundations. Proceedings of the offshore technology conference, Houston, TX, USA, paper OTC 6026.

Shen, Z., Bie, S. \& Guo, L. (2017). Undrained capacity of a surface circular foundation under fully three-dimensional loading. Comput. Geotech. 92, 57-67.

Shen, Z., Feng, X. \& Gourvenec, S. (2016). Undrained capacity of surface foundations with zero-tension interface under planar V-H-M loading. Comput. Geotech. 73, 47-57.

$\mathrm{Si}$, H. (2015). TetGen, a Delaunay-based quality tetrahedral mesh generator. ACM Trans. Math. Software 41, No. 2, article no. 11 .

Taiebat, H. A. \& Carter, J. P. (2000). Numerical studies of the bearing capacity of shallow foundations on cohesive soil subjected to combined loading. Géotechnique 50, No. 4, 409-418, https://doi.org/10.1680/geot.2000.50.4.409.

Taiebat, H. A. \& Carter, J. P. (2010). A failure surface for circular footings on cohesive soils. Géotechnique 60, No. 4, 265-273, https://doi.org/10.1680/geot.7.00062.

Tan, F. (1990). Centrifuge and theoretical modelling of conical footings on sand. $\mathrm{PhD}$ thesis, University of Cambridge, Cambridge, UK.

Terzaghi, K. (1943). Theoretical soil mechanics. New York, NY, USA: John Wiley and Sons.

Vesić, A. (1973). Analysis of ultimate loads of shallow foundations. J. Soil Mech. Found. Div., ASCE 99, No. 1, 45-73.

Vulpe, C. (2015). Design method for the undrained capacity of skirted circular foundations under combined loading: effect of deformable soil plug. Géotechnique 65, No. 8, 669-683, https://doi.org/10.1680/geot.14.P.200.

Vulpe, C., Gourvenec, S. \& Power, M. (2014). A generalised failure envelope for undrained capacity of circular shallow foundations under general loading. Géotechnique Lett. 4, No. 3, 187-196, https://doi.org/10.1680/geolett.14.00010.

Zhang, Y., Bienen, B., Cassidy, M. J. \& Gourvenec, S. (2011). The undrained bearing capacity of a spudcan foundation under combined loading in soft clay. Mar. Structs 24, No. 4, $459-477$. 